\title{
Periportal and sinusoidal liver dendritic cells suppressing T helper type 1-mediated hepatitis
}

\author{
Tomohiro Watanabe, Hiroaki Katsukura, Tsutomu Chiba, Toru Kita, Yoshio Wakatsuki
}

Gut 2007;56:1445-1451. doi: 10.1136/gut.2007.121251

See end of article for authors' affiliations

Correspondence to:

Y Wakatsuki, Department of

Clinical Bio-regulatory

Science, Kyoto University

Graduate School of

Medicine, Shogoin

Kawahara-cho 54, Sakyo-

ku, Kyoto 606-8507, Japan;

wakatsu@kuhp.kyoto-u.ac.jp

Revised 8 May 2007

Accepted 14 May 2007
Background: Recently, we found that portal vein tolerance is associated with generation of Th2 cells and apoptosis of Th1 cells in the liver, which is regulated by antigen (Ag)-presenting dendritic cells (DCs) in the periportal area and sinusoids.

Aim: In this study, we tested whether the periportal and sinusoidal DCs, which were loaded with an Ag in vivo, can inhibit liver injury caused by Thl cells activated by the Ag administered systemically.

Methods: Ag-specific hepatitis model was created by adoptively transferring ovalbumin (OVA)-specific CD4 ${ }^{+}$ T cells to BALB/c mice and venous injection of OVA-containing liposomes. Liver CD1 $1 c^{+}$cells obtained from mice fed OVA were then transferred into these mice.

Results: The transfer of liver $\mathrm{CD} 11 \mathrm{c}^{+}$cells from OVA-fed mice completely inhibited hepatic injury, which was associated with apoptosis of OVA-specific CD4 ${ }^{+} \mathrm{T}$ cells and emergence of Th2 cells in the liver. Transfer of $\mathrm{CD} 11 \mathrm{c}^{+}$cells and subcutaneous OVA challenge led to enhancement of OVA-specific lgE Ab as well as Th2 cytokine responses in the recipient mice.

Conclusions: Periportal and sinusoidal DCs loaded with an Ag in the portal vein can induce Th2 response in the liver and prevent hepatic injury caused by Thl cells.
A lthough portal blood flow contains various antigens (Ags) derived from foods and intestinal microflora, the liver normally evades such inflammatory responses that would lead to tissue injury. This immunological hyporesponsiveness, which is called portal vein tolerance, ${ }^{12}$ explains several immunological properties of the liver. First, the liver is such a tolerogenic organ that transplantation of an allogenic liver sometimes requires little immunosuppressive therapy. ${ }^{3}{ }^{3}$ Second, surgical diversion of portal blood away from the liver abrogates oral tolerance. ${ }^{5}$ Third, pancreatic islet cells transplanted via the portal vein evades rejection by the host and cures insulin-dependent diabetes. ${ }^{6}$ Thus, portal vein tolerance can establish hyporesponsiveness to Ags migrating to the liver through portal blood flow.

Regarding the induction mechanisms of portal vein tolerance, Ag-presenting cells (APCs), such as Kupffer cells, liver sinusoidal endothelial cells (LSECs) and dendritic cells (DCs), are known to play important roles in the liver. ${ }^{7}$ For example, Ag-presentation by LSECs and DCs preferentially leads to development of Th2 cells producing anti-inflammatory cytokines. ${ }^{8-10}$ In contrast to these tolerogenic responses, some Agpresentations in the liver can result in the production of tissuedamaging $\mathrm{T}$ cells, which leads to autoimmune liver diseases such as autoimmune hepatitis (AIH), primary biliary cirrhosis (PBC), and primary sclerosing cholangitis (PSC). In these latter situations, a marked increase of Thl type cytokines is known to play an important role in the establishment of the diseases. ${ }^{11-13}$ This was corroborated by the studies of experimental hepatitis and cholangitis, which has revealed a pathogenic role played by Thl cytokines. ${ }^{14}{ }^{15}$

Recently, we found that an Ag administered orally can activate Ag-specific $\mathrm{CD} 4^{+} \mathrm{T}$ cells in the liver and increase the number of Th2 cells, which associates with Fas-mediated apoptosis of Thl cells. ${ }^{16}$ We reported that Ag-capturing CDllc ${ }^{+}$ cells in the liver are defective in IL12 secretion and responsible for the generation of Th2 cells. ${ }^{8}$

Based on these findings, we speculated that DCs play pivotal roles in the induction of portal vein tolerance. Here we show that adoptive transfer of liver CDI Ic ${ }^{+}$DCs loaded with an $\mathrm{Ag}$ in the portal vein can suppress Thl-mediated liver injury in the recipient mice.

\section{METHODS}

Animals and protocol for immunisation

DO11.10 mice with $\mathrm{T}$ cells bearing the transgenic $\mathrm{T}$ cell receptor (TCR) that recognises the 323-339 peptide fragment of ovalbumin (OVA) in the context of $\mathrm{IA}^{\mathrm{d}}$ were crossed to $\operatorname{Rag}_{2}-/-$ mice. ${ }^{8}$ BALB/C and $\operatorname{Rag}_{2}-/-$ DO11.10 mice were housed under specific pathogen free conditions in the Animal Facility of Kyoto University. Male BALB/c mice were fed 100mg of OVA (Sigma Chemical Co., St Louis, Missouri, USA) or PBS alone, every other day for a total of five times by intragastric intubation. All animal experiments were performed in accordance with institutional guidelines and ethical permission for this study was granted by the review board of Kyoto University.

\section{Histological analysis}

Liver sections were stained with biotinylated anti-CDIlc (Pharmingen, San Diego, California, USA), anti-IA ${ }^{\mathrm{d}}$ (Pharmingen), and anti-F4/80 Ab (Serotec Ltd, Oxford, England) as described previously. ${ }^{17}$ For the detection of apoptotic hepatocytes, TdT-mediated dUTP nick-end labelling (TUNEL)-staining was performed using a commercial kit (apoTACS-DAB, Trevigen, Gaithersburg, Maryland, USA).

Preparation of mononuclear cells from the spleen, the lymph nodes, and the liver

Lymphocytes from the spleen and draining lymph nodes (dLNs) were prepared as previously described. ${ }^{8}$ Intrahepatic lymphocytes (IHLs) were prepared following the method

Abbreviations: Ag, antigen; APC, antigen presenting cell; LSEC, liver sinusoidal endothelial cell; DC, dendritic cell; $\mathrm{AlH}$, autoimmune hepatitis; PBC, primary biliary cirrhosis; PSC, primary sclerosing cholangitis; TUNEL, TdT-mediated dUTP nick-end labelling; IHL, intrahepatic lymphocyte; PI, propidium iodide; AST, aspartate aminotransferase; ALT, alanine aminotransferase; dLN, draining lymph nodes 
A
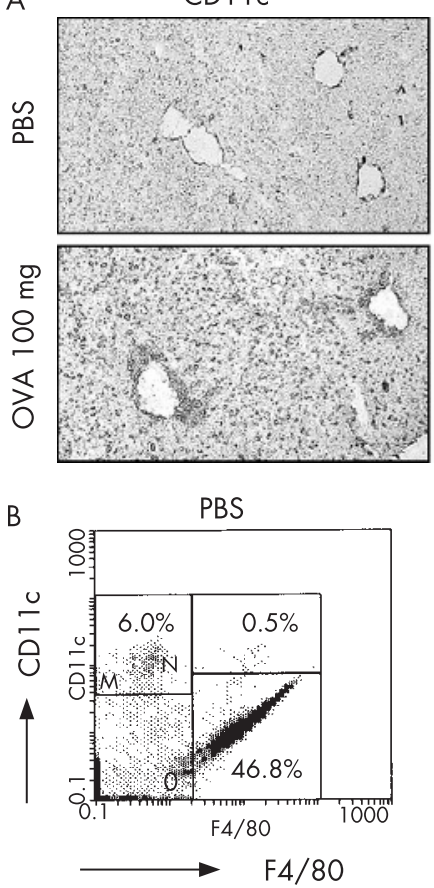

IAd
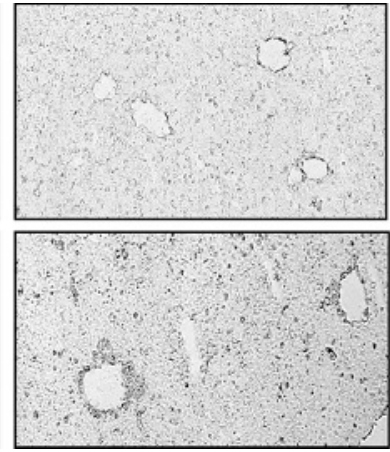

\section{OVA $100 \mathrm{mg}$}

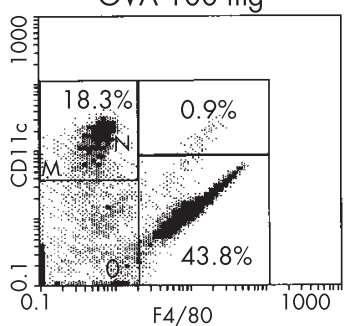

$\mathrm{F} 4-80$

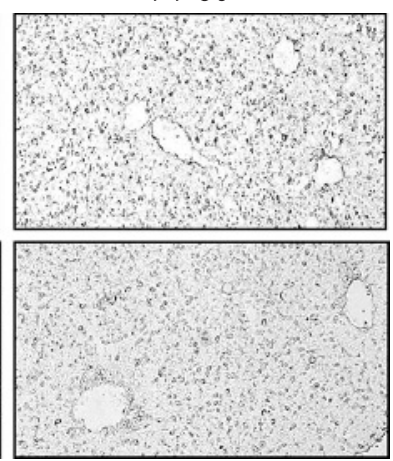

25.2.
Figure 1 Characterisation of $\mathrm{CD} 11 \mathrm{c}^{+}$cells in the liver of $B A L B / c$ mice fed OVA. BALB/c mice were fed $100 \mathrm{mg}$ of OVA or PBS every other day for a total of five times and killed 3 days after the fifth feeding. (A) Localisation of $C D 11 \mathrm{c}^{+}, \mid \mathrm{A}^{\mathrm{d}+}, \mathrm{F} 4 / 80^{+}$cells in the liver.

Frozen liver sections were stained with anti$C D 1$ lc $m A b$, anti-IA ${ }^{d} m A b$, or anti-F4/80 $m A b$. (B) Flow-cytometric analysis of nonparenchymal low density cells in the liver.

Cells were stained with PE-conjugated anti$\mathrm{CD} 1 \mathrm{lc} \mathrm{mAb}$ and biotin-conjugated anti-F4/ $80 \mathrm{mAb}$ followed by incubation with streptavidin-FITC. Dead cells were excluded by propidium iodide (PI) staining. The number shows the percentage of cells in each region. (C) $C D 11 \mathrm{c}^{+}$cells are isolated from the liver of mice fed PBS or OVA. These cells were stained with $\mathrm{PE}$-conjugated control $\mathrm{Ab}$, anti-IA $\mathrm{mAb}$, anti-CD80 mAb, and anti-

CD86 mAb. The results shown are representative one of two experiments $(n=4$ in each group).
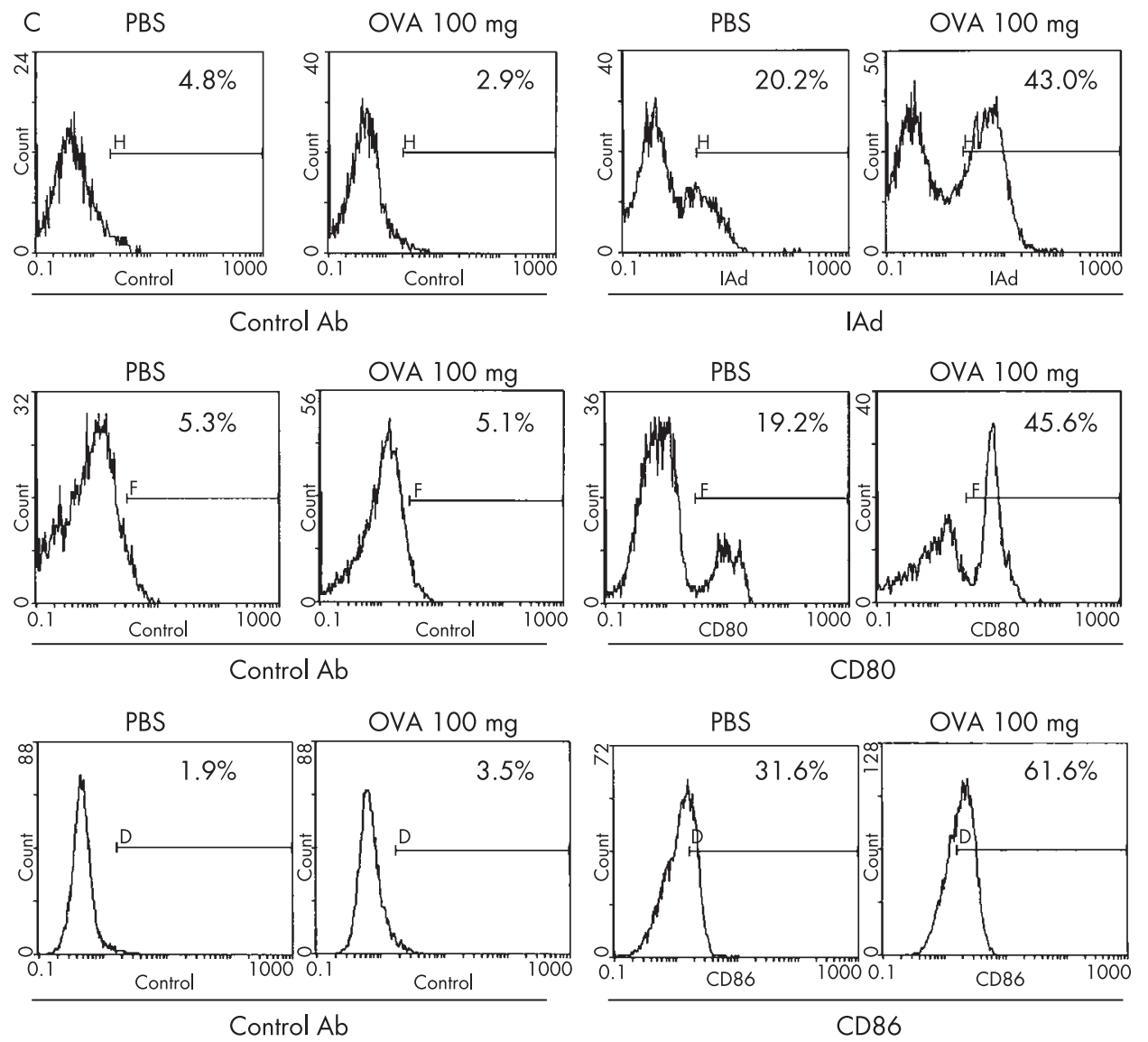

described previously. ${ }^{16}$ Hepatic low density non-parenchymal cells were also obtained as described previously. ${ }^{8}$

\section{Adoptive transfer of CD $11 c^{+}$cells to naive BALB/c mice} Splenic and hepatic $\mathrm{CDIIC}^{+}$cells were purified by positive selection using autoMACS (Miltenyi Biotec, Bergisch Gladback, Germany) as described previously. ${ }^{8}$ The recovered cells were more than $90 \% \mathrm{CDIlc}^{+}$(confirmed by flow cytometric analysis). Six-week old BALB/c mice were injected intravenously with $5 \times 10^{5} \mathrm{CDI}_{1 \mathrm{C}^{+}}$cells purified from the spleen or the liver of BALB/C mice fed OVA or PBS. The next day after the transfer, the recipient mice were immunised subcutaneously with complete Freund's adjuvant (CFA, GIBCO BRL, Grand Island, New York, USA) and OVA ( $1 \mathrm{mg} / \mathrm{ml})$. OVA-specific IgG, IgGl, IgG2a, IgE Ab were measured by ELISA as described elsewhere. ${ }^{18}$ 

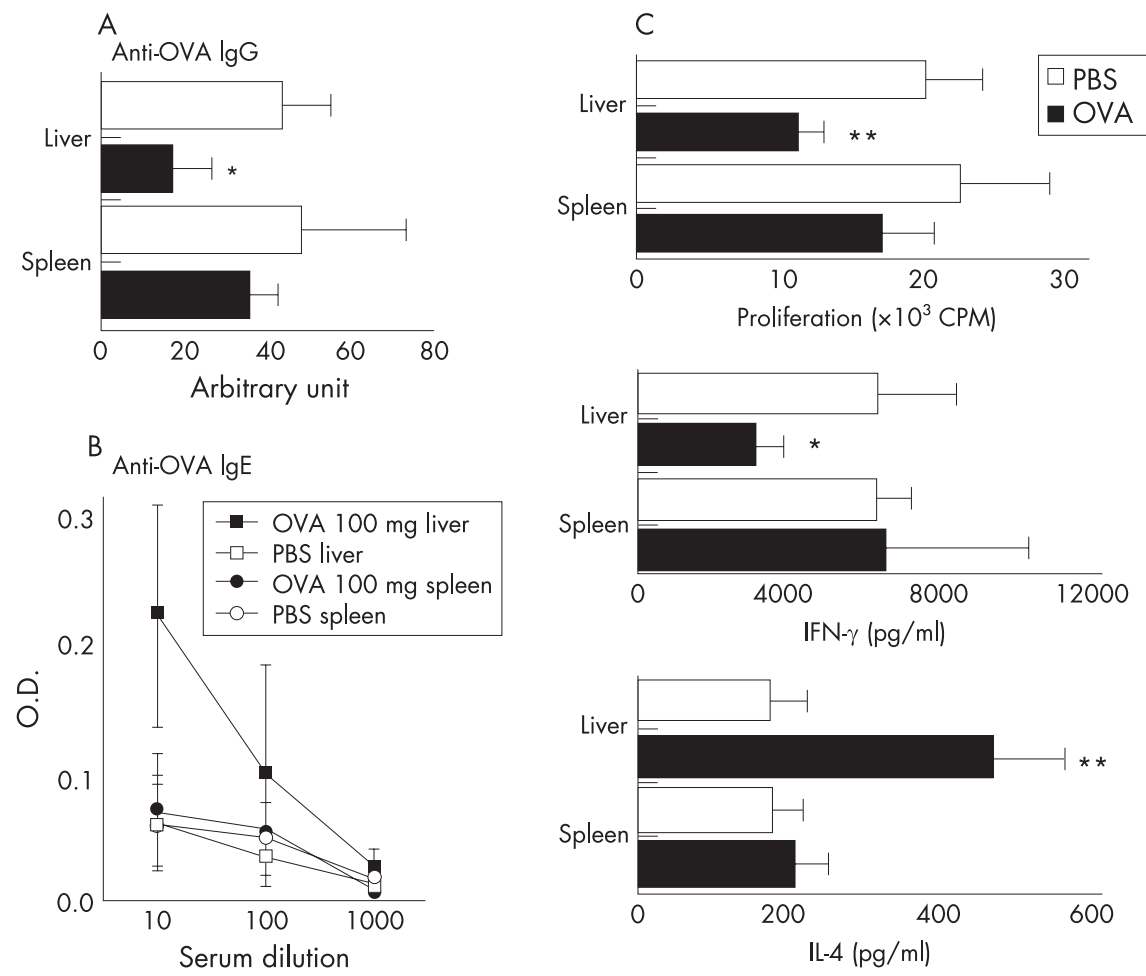

Figure 2 OVA-specific $A b$ and cytokine responses in the mice transferred with hepatic CDI lc cells. Donor BALB/c mice were fed $100 \mathrm{mg}$ of OVA or PBS every other day for a total of five times and killed 3 days after the fifth feeding. Hepatic or splenic $\mathrm{CD} 11 \mathrm{c}^{+}$cells of the donor mice were transferred into recipient $\mathrm{BALB} / \mathrm{c}$ mice via intravenous route $\left(5 \times 10^{5} /\right.$ mouse). The day after the transfer, recipient mice were immunised subcutaneously with $100 \mu \mathrm{g}$ of OVA. Serum OVA-specific $\lg G A b(A)$ and OVA-specific lgE $A b$ responses (B) of the recipient mice were measured 14 days after the subcutaneous immunisation. Pooled immune sera obtained from BALB/c mice that received repeated immunisation with OVA were used as control, and the Ab titre equivalent to $2^{10}$ dilution of immune sera was defined as one arbitrary unit (A). (C) Proliferative responses, IFN- $\gamma$ secretion, and IL4 secretion by dLN-CD4 ${ }^{+}$T cells were measured 10days after the subcutaneous immunisation. $\mathrm{CD}^{+} \mathrm{T}$ cells $\left(1 \times 10^{5} /\right.$ well $)$ were stimulated by OVA $(0.1 \mathrm{mg} / \mathrm{ml})$ presented by irradiated splenocytes $\left(5 \times 10^{5}\right)$ well) from $B A L B / c$ mice. For proliferative responses, the cultures were incubated for 72 hours and $1 \mu \mathrm{Ci}$ of $\left[{ }^{3} \mathrm{H}\right]$ thymidine was added for the final 16 hours. For cytokine analysis, culture supernatants were collected at 48 hours for IFN- $\gamma$ production and at 72 hours for IL4 production. The results are expressed as meanSD. ${ }^{*} p<0.05,{ }^{* *} p<0.01$ versus PBS control. The results shown are representative one of two independent experiments ( $n=4$ in each group).

\section{Induction of Ag-specific hepatic injury}

Six-week old BALB/c mice were injected intravenously with $5 \times 10^{5} \mathrm{CD}_{11 \mathrm{C}^{+}}$cells purified from the liver of BALB/c mice fed OVA or PBS as described above. OVA-specific liver injury using OVA-liposome was induced in these recipient mice as reported previously with some modifications.$^{14}$ Briefly, splenocytes from $\mathrm{Rag}_{2}-/-$ DO11.10 mice were stimulated for 3days with $\mathrm{OVA}_{323-}$ 339 peptide $(1 \mu \mathrm{g} / \mathrm{ml})$ and then activated OVA-specific $\mathrm{CD}^{+} \mathrm{T}$ cells were purified by positive selection using autoMACS (>90\% KJl-26 ${ }^{+}$, confirmed by flowcytometric analysis). $\mathrm{BALB} / \mathrm{c}$ mice that received $\mathrm{CDIlc}^{+}$cells were treated with intravenous injection of OVA-containing liposome $(15 \mathrm{mg}$, NOF corporation, Tokyo, Japan) followed by the transfer of activated splenic $\mathrm{CD}^{+} \mathrm{KJ} 1-26^{+} \mathrm{T}$ cells 2 hours later $\left(2.5 \times 10^{6} /\right.$ mouse $)$. Mice were killed 16hours later and then serum, IHLs, and splenocytes were prepared. The liver injury was assessed by serum aspartate aminotransferase (AST) and alanine animotransferase (ALT) activities by a commercial kit (Wako, Osaka, Japan).

\section{Stimulation of draining lymph nodes (dLN)-cells, spleen cells, and IHLs}

$\mathrm{CD}^{+} \mathrm{T}$ cells were purified from the spleen, $\mathrm{dLN}$, and the liver by positive selection using autoMACS (Miltenyi Biotec, Bergisch Gladback, Germany). These $\mathrm{CD} 4^{+} \mathrm{T}$ cells $\left(1 \times 10^{5} /\right.$ well $)$ were stimulated in vitro with OVA $(0.1 \mathrm{mg} / \mathrm{ml})$ or OVA-peptide $(1 \mu \mathrm{g} / \mathrm{ml})$ presented by irradiated splenocytes $\left(5 \times 10^{5} /\right.$ well $)$ from $\mathrm{BALB} / \mathrm{c}$ mice. The cultures were incubated for 72 hours and $1 \mu \mathrm{Ci}$ of $\left[{ }^{3} \mathrm{H}\right]$ thymidine was added for the final 16hours. Proliferation and cytokine production were evaluated as described previously. ${ }^{19}$ In some experiments, splenic OVAspecific $\mathrm{CD}^{+} \mathrm{T}$ cells $\left(1 \times 10^{5} /\right.$ well $)$ were stimulated with OVApeptide $(1 \mu \mathrm{g} / \mathrm{ml})$ presented by hepatic CDllc cells $\left(1 \times 10^{5} /\right.$ well) in the presence of mouse ILl2 (10ng/ml, Peprotec), rat

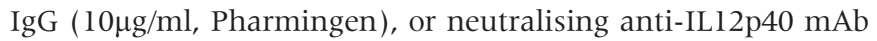

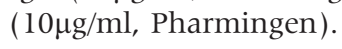

\section{mAbs and flow cytometry}

FITC-conjugated KJl-26 recognising transgenic TCR specific to OVA and biotin-conjugated F4/80 mAb were purchased from Caltag (San Francisco, California, USA). FITC or PE-conjugated anti-mouse CDllc mAb, PE-conjugated anti-mouse CD4, IA ${ }^{\mathrm{d}}$, CD80, CD86 mAb and biotin-conjugated Annexin V were purchased from Pharmingen. Streptavidin-RED670 was obtained from Life Technologies. Surface immunofluorescence was assessed as described previously. ${ }^{16}$

\section{Statistical analysis}

Student's t-test was used to evaluate the significance of the differences. Statistical analysis was performed with the Stat View v.4.5 program (Abacus Concepts, Berkeley, CA). A p value $<0.05$ was regarded as statistically significant.

\section{RESULTS}

\section{Activation of liver DCs upon oral administration of an} $\mathrm{Ag}$

As our previous study indicated that a part of OVA administered orally is carried to the liver and co-localise with class II $\left(\mathrm{IA}^{\mathrm{d}}\right)^{+}$cells in the periportal area, ${ }^{8}$ we analysed tissue localisation of DCs in the liver by staining class II and CDIlc antigens (fig 1A). Class $\mathrm{II}^{+}$and $\mathrm{CDllc} \mathrm{c}^{+}$cells were mainly localised in the periportal area of the liver of PBS-fed mice. In mice fed OVA, numbers of class $\mathrm{II}^{+}$and $\mathrm{CD} 1 \mathrm{lc}^{+}$cells increased not only in the periportal area but also in the sinusoidal area. No increase was seen in $\mathrm{F} 4 / 80^{+}$Kupffer cells that localised mainly sinusoidal area. To analyse quantitatively and to discriminate between DCs and Kupffer cells, we did dual staining flow-cytometric analysis by using hepatic low density 
A

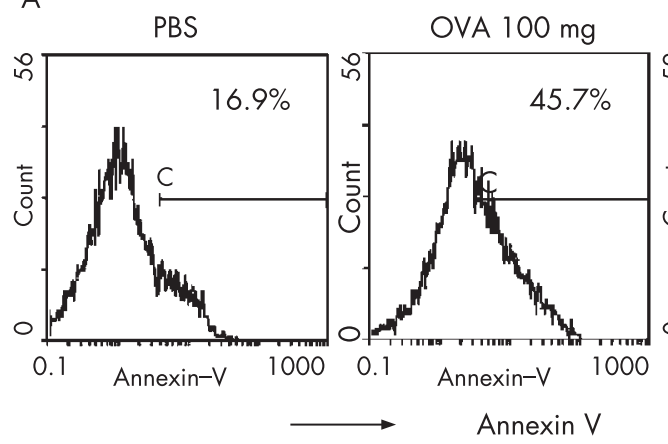

B

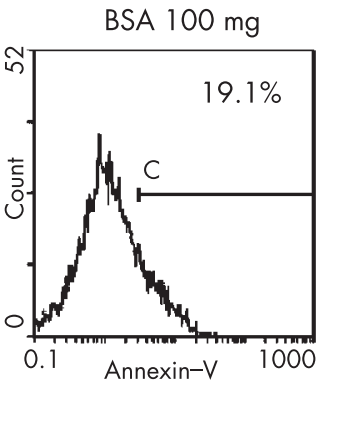

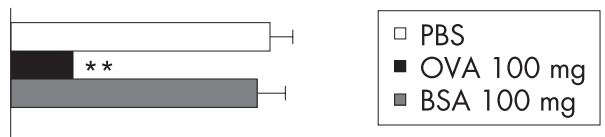

010002000300040005000 IFN- $\gamma(\mathrm{pg} / \mathrm{ml})$

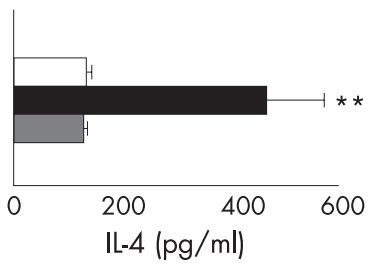

C

rIL-12

all-12 Ab
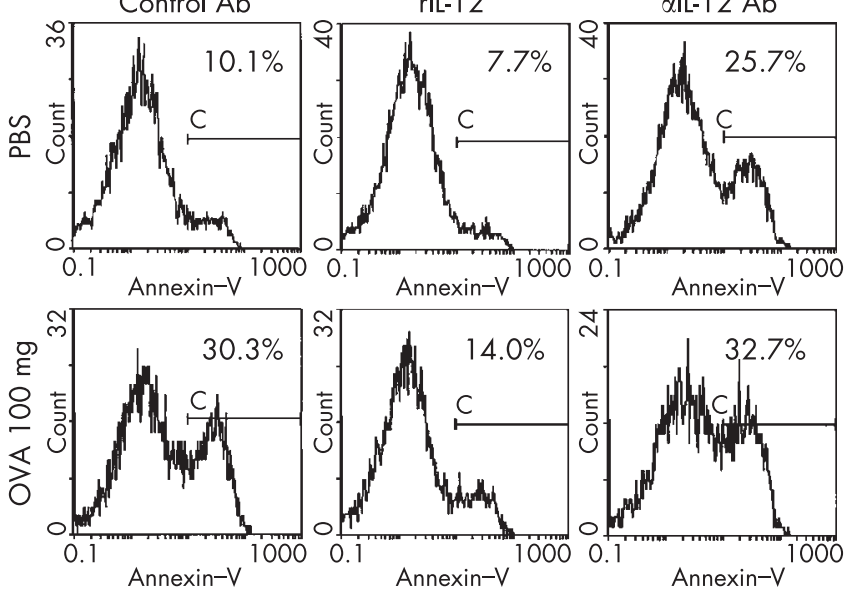

$14.0 \%$
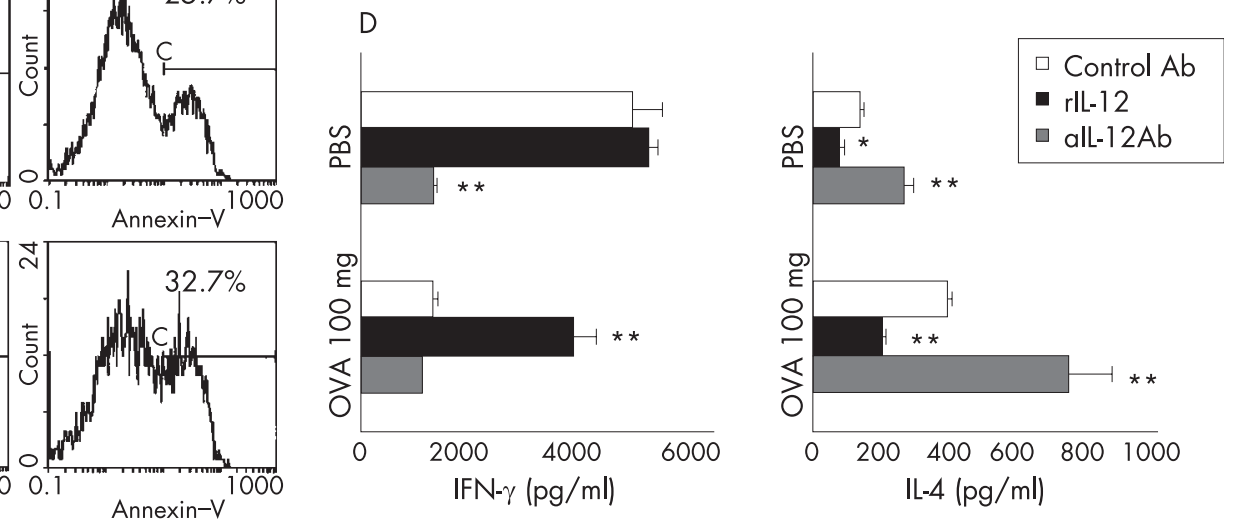

Figure 3 IL12 deficiency in liver DCs is responsible for Th2 responses and apoptosis. Naiive OVA-specific CD4 $4^{+}$cells $\left(1 \times 10^{5} /\right.$ well) isolated from the spleen of $\operatorname{Rag}_{2}-/-D O 11$. Ten mice were stimulated with OVA-peptide $(1 \mu \mathrm{g} / \mathrm{ml})$ in the presence of hepatic CD1 $1 \mathrm{c}^{+}$cells $\left(1 \times 10^{5} /\right.$ well) isolated from mice fed PBS, BSA, or OVA. (A) Cells were cultured for 48 hours and the percentage of Annexin $\mathrm{V}^{+}$cells in OVA-specific CD $4^{+} \mathrm{KJ} 1-26^{+} \mathrm{T}$ cells was determined. Cells were stained with FITC-conjugated Annexin $\mathrm{V}$ and PE-conjugated KJ1-26 mAb. Analysis gate was set on KJ1-26 cells. The number in each panel shows the percentage of Annexin $\mathrm{V}^{+}$cells. (B) Production of IFN- $\gamma$ and IL4 by OVA-specific CD4 ${ }^{+}$T cells. Culture supernatants were collected at 48 hours for IFN- $\gamma$ production and at 72 hours for IL4 production. (C, D) Effects of IL 12 signalling on induction of apoptosis and generation of Th2 responses by hepatic CDI l c cells. Anti-IL-12p40 mAb $(10 \mu \mathrm{g} / \mathrm{ml})$, control Ab $(10 \mu \mathrm{g} / \mathrm{ml})$, or mouse IL12 $(10 \mathrm{ng} / \mathrm{ml})$ were added to the culture. The percentage of Annexin $\mathrm{V}^{+}$ cells in OVA-specific CD4 ${ }^{+} \mathrm{KJ} 1-26^{+} \mathrm{T}$ cells (C) and production of IFN- $\gamma$ and IL4 (D) were determined as described above. ${ }^{*} p<0.05$, ${ }^{* *} p<0.01$ versus PBS control (B) or Control Ab (D). The results shown are representative one of two independent experiments ( $n=3$ in each group).

non-parenchymal cells (fig 1B). Most $\mathrm{CDIlc}^{+}$cells were negative for F4/80 staining, suggesting that these CDl $\mathrm{c}^{+}$cells are DCs rather than Kupffer cells. Consistent with the results of tissue staining, the percentage of $\mathrm{CDIlc}^{+}$cells was markedly increased in the liver of OVA-fed mice. As shown in fig $\mathrm{IC}$, the percentages of $\mathrm{CDI}_{1 \mathrm{C}^{+}}$DCs expressing class II, CD80, and CD86 were all increased in the liver by oral administration of OVA. Thus, these flow-cytometric and immunohistochemical analyses indicated that OVA feeding associates with activation of DCs in the liver.

\section{Systemic Th2 response elicited by liver DCs}

Next, we assessed the functional properties of in vivo Ag-loaded $\mathrm{CDIlc}^{+}$cells by adoptively transferring them into naïve recipient mice. For this purpose, hepatic or splenic $\mathrm{CDIlc}^{+}$ cells from donor BALB/C mice fed OVA or PBS were transferred into the recipient $\mathrm{BALB} / \mathrm{C}$ mice, which were immunised subcutaneously with OVA/CFA after the transfer. As shown in fig 2A, OVA-specific IgG Ab responses were significantly reduced in the recipient mice which received hepatic $\mathrm{CD} 1 \mathrm{lc}^{+}$ cells of OVA-fed mice while the ratio of OVA-specific $\operatorname{IgG}_{1} \mathrm{Ab} /$ $\operatorname{IgG}_{2 \mathrm{a}} \mathrm{Ab}$ was not altered (data not shown). In contrast, OVAspecific IgE Ab responses were significantly enhanced in the recipient mice transferred with hepatic $\mathrm{CD}_{11 \mathrm{C}^{+}}$cells from OVAfed mice (fig $2 \mathrm{~B}$ ), suggesting that Th2 response occurred in the recipient mice. This was exactly the case as IL4 secretion by dLN-CD4 ${ }^{+} \mathrm{T}$ cells was markedly increased while OVA-specific proliferative responses and secretion of IFN- $\gamma$ were significantly decreased in those mice (fig 2C). The effect on cytokine production was Ag-specific as anti-CD3 stimulation showed no differences (data not shown). In contrast to the CDllc ${ }^{+}$cells in the liver, those taken from the spleen of mice fed either OVA or PBS did not alter cytokine or Ab responses. Taken together, CD $1 \mathrm{lc}^{+}$DCs in the liver, not in the spleen, of mice administered OVA orally were sufficient to transfer Th2 response to OVA in the recipient mice.

\section{A mechanism of Th2 differentiation by liver DCs}

As we knew that liver $\mathrm{CD}_{11 \mathrm{C}^{+}}$cells loaded an $\mathrm{Ag}$ in vivo can induce Th2 differentiation of naïve $\mathrm{CD}^{+} \mathrm{T}$ cells by Fasmediated apoptosis of Thl cells, ${ }^{8}$ we assessed whether Agspecific killing was occurring in our model. For this purpose, hepatic CDIlc ${ }^{+}$cells isolated from mice fed PBS, BSA, or OVA were cultured with naïve OVA-specific $\mathrm{CD}^{+} \mathrm{T}$ cells from $\mathrm{Rag}_{2}-/-$ DOl 1.10 mice. We saw an increase of Annexin $\mathrm{V}^{+}$OVAspecific $\mathrm{CD}^{+} \mathrm{T}$ cells in the culture with DCs of OVA-fed mice, which was associated with a decrease of IFN- $\gamma$ and an increase of IL4 production (fig 3A, B). In contrast, the liver DCs of BSAfed mice did not alter the percentage of Annexin $\mathrm{V}^{+}$cells or cytokine production. Thus, direction of Th2 differentiation by 


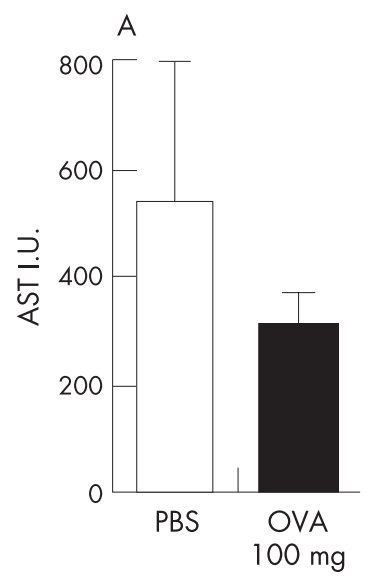

B
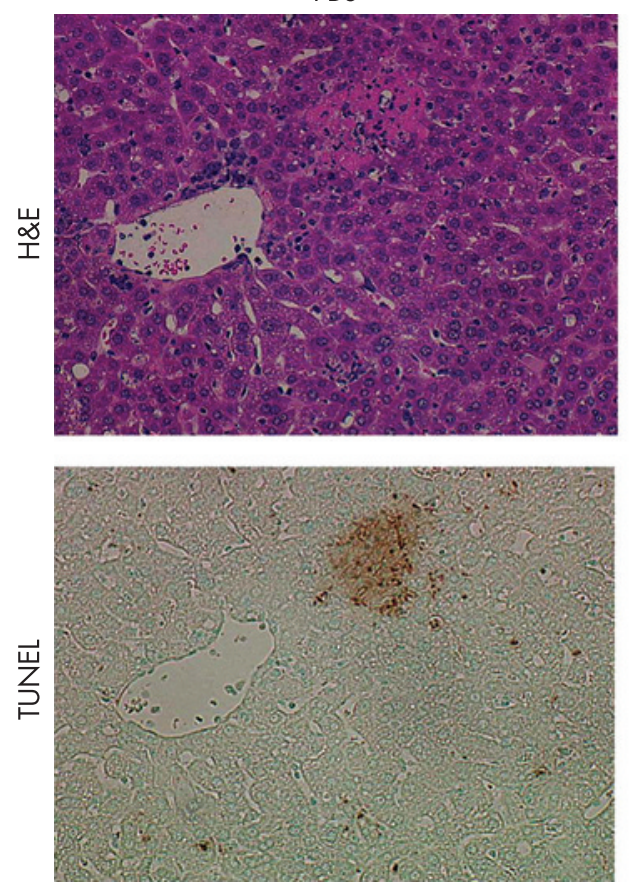

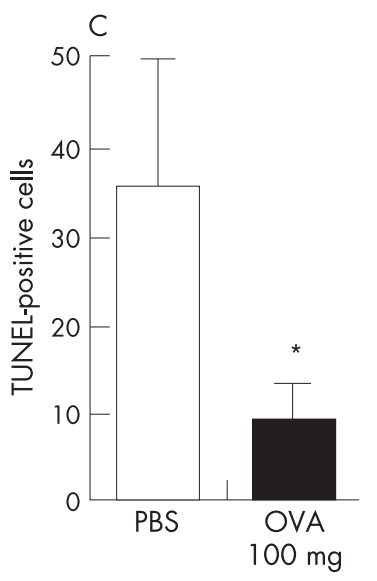

OVA $100 \mathrm{mg}$
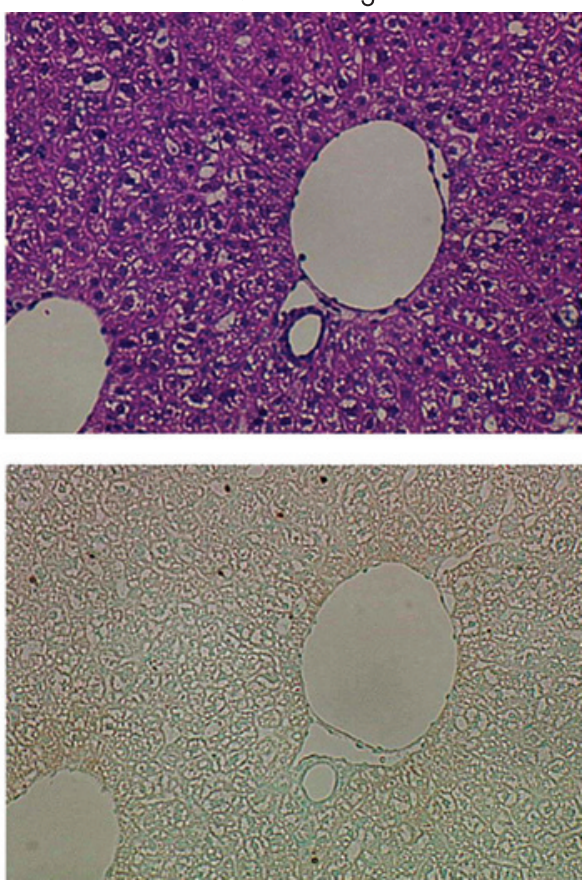

Figure 4 Inhibition of development of OVA-specific hepatitis by adoptive transfer of hepatic CD1 l c cells. Donor BALB/c mice were fed $100 \mathrm{mg}$ of OVA or PBS every other day for a total of five times and killed 3 days after the fifth feeding. Hepatic CDI l c cells of donor mice were transferred into the recipient $\mathrm{BALB} / \mathrm{c}$ mice via intravenous route $\left(5 \times 10^{5} /\right.$ mouse). The day after the CD1 $1 c^{+}$ cell transfer, recipient mice were treated with intravenous injection of $0.3 \mathrm{ml}$ of $50 \mathrm{mg} / \mathrm{ml}$ OVA-containing liposome and in vitro activated OVA-specific $\mathrm{CD} 4^{+} \mathrm{T}$ cells $\left(2.5 \times 10^{6} /\right.$ mouse $)$. Mice were killed 16 hours after the induction of hepatitis. (A) Serum levels of AST and ALT. (B) Liver sections staining with $\mathrm{H} \& E$ and TUNEL in the mice transferred with hepatic $C D 11 c^{+}$cells of PBS or OVA-fed mice. (C) The number of TUNEL ${ }^{+}$hepatocytes. TUNEL ${ }^{+}$cells are counted in high power fields. ${ }^{*} p<0.05$, versus PBS control. The results are expressed as mean SD. The results shown are representative one of two independent experiments ( $n=4$ in each group). liver DCs involves Ag-presentation and apoptosis of Ag-specific CD4 T cells.

To assess how the above phenomenon relates to the property of DCs, which are deficient in IL12 secretion and cause apoptosis, ${ }^{8}$ we neutralised and restored IL12 signalling by anti-IL12p40 mAb and recombinant IL12, respectively. The percentage of Annexin $\mathrm{V}^{+}$OVA-specific $\mathrm{CD}^{+} \mathrm{T}$ cells and IL4 production were markedly increased when anti-IL12 mAb was added to the culture containing liver DCs of PBS-fed mice (fig 3C, D). In contrast, the percentage of apoptotic cells and IL4 production were decreased when IL12 was added to the culture containing liver DCs of OVA-fed mice. Thus, blockade of IL12 signalling in liver DCs of PBS-fed mice had Th2-inducing function similar to that of DCs of OVA-fed mice. Conversely, restoration of IL12 signalling in liver DCs of OVA-fed mice abrogated Th2 induction. Taken together, these data suggest that deficiency in IL12 secretion by liver DCs of OVA-fed mice is responsible for Th2 differentiation and apoptosis of naïve OVAspecific $\mathrm{CD}^{+}{ }^{\mathrm{T}}$ cells.

Inhibition of hepatitis by adoptive transfer of liver DCs In our final series of experiments, we assessed the in vivo function of liver DCs in the OVA-specific hepatitis model which utilises intravenous injection of OVA-liposome and adoptive transfer of pre-activated OVA-specific $\mathrm{CD} 4^{+} \mathrm{T}$ cells. ${ }^{14}$ In the mice that received hepatic $\mathrm{CD} 1 \mathrm{lc}^{+}$cells of control mice, elevations of serum AST and ALT levels were seen (fig 4A). Compatible with this, H\&E and TUNEL staining revealed mononuclear cell infiltration in the periportal region and focal necrosis of hepatocytes in the liver of these mice (fig 4B, C). In contrast, elevation of serum levels of transaminases or necrosis of hepatocytes was not seen in the mice which received cells obtained from OVA-fed mice (fig 4A, C). Thus, adoptive transfer of liver DCs from OVA-fed mice abolished the development of hepatitis in the recipient mice. The prevention of hepatitis was associated with OVA-specific Th2 responses in the liver. As shown in fig 5A, OVA-specific IL4 production by hepatic $\mathrm{CD}^{+} \mathrm{T}$ cells was markedly increased in mice received liver $\mathrm{CDIlic}^{+}$cells of OVA-fed mice. In contrast, OVA-specific proliferative response and IFN- $\gamma$ production were significantly decreased in these mice. Finally, we studied the population of hepatic $\mathrm{CD} 4^{+} \mathrm{KJ} 1-26^{+} \mathrm{T}$ cells that were specific to OVA and causing hepatitis. As shown in fig 5B, compared to control, the percentage of $\mathrm{CD}^{+} \mathrm{KJ}-26^{+} \mathrm{T}$ cells in the liver was remarkably reduced in the mice that received hepatic CD1 $1 \mathrm{c}^{+}$cells of OVAfed mice. The total number of IHLs was significantly reduced in 

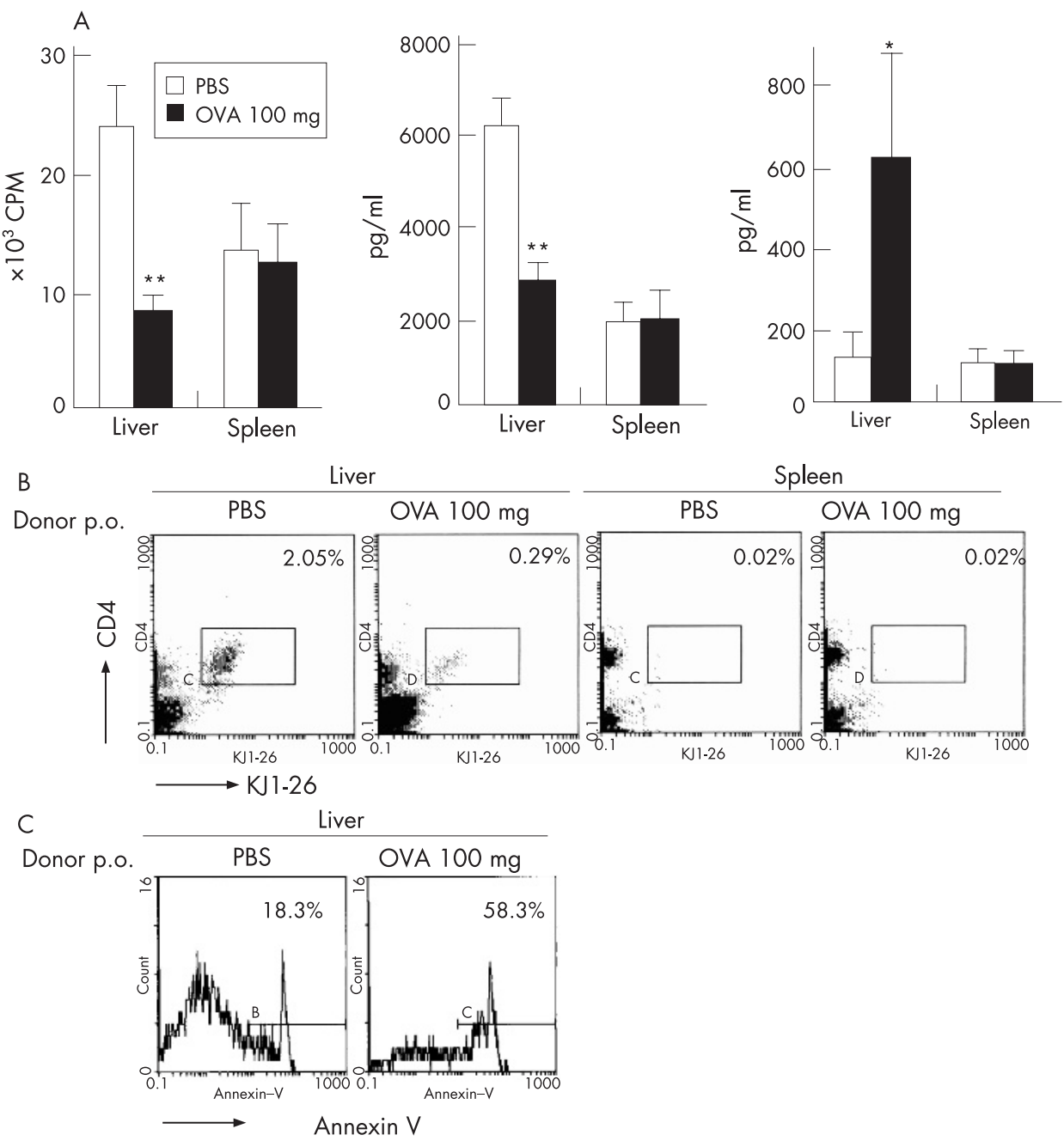

those mice (PBS versus OVA, 3.81 (SD 8) $\times 10^{6} /$ mouse versus $1.90($ SD 6$\left.) \times 10^{6}\right)$, suggesting that adoptive transfer of hepatic $\mathrm{CDIIC}^{+}$cells from OVA-fed mice inhibited clonal expansion of OVA-specific $\mathrm{CD}^{+} \mathrm{T}$ cells. Furthermore, this inhibition was caused by apoptosis as the percentage of Annexin $\mathrm{V}^{+}$cells in $\mathrm{CD} 4^{+} \mathrm{KJ} 1-26^{+} \mathrm{T}$ cells was significantly increased in the liver of mice received hepatic CDIlc ${ }^{+}$cells of OVA-fed mice (fig 5C). Taken together, these data suggest that adoptive transfer of liver DCs loaded of OVA in vivo deleted Thl cells and suppressed hepatitis in recipient mice.

\section{DISCUSSION}

Utilising an experimental hepatitis model, we show here that the dual blood flow system, systemic and portal, serves to maintain immunological homeostasis in the liver. This was indicated by the fact that an inflammatory response elicited by a systemic OVA challenge is counter-regulated by another response to OVA migrating via the portal blood flow. This counter-regulation was achieved by the function of periportal and sinusoidal CDllc ${ }^{+}$cells.

Three populations of APCs are known to reside in the liver; Kupffer cells, DCs, and LSECs. Depending on the type of APCs, immune responses elicited are different in their spectra of inflammation in the liver. One such example is the case with DCs derived from GM-CSF stimulated progenitors in the liver. The DCs, upon injection to allogenic recipients, activate $\mathrm{T}$ cells secreting anti-inflammatory cytokines such as IL4 and IL10. ${ }^{10}$ Another report shows that liver-derived DEC205 ${ }^{+} \mathrm{B} 220^{+} \mathrm{CD} 19^{-} \mathrm{DC}$ induce apoptosis of activated T cells. ${ }^{20}$
Figure 5 Cytokine production and apoptosis of OVA-specific CD4 $4^{+} \mathrm{T}$ cells in the liver. OVA-specific hepatic injury was induced in $B A L B / c$ recipient mice transferred with hepatic $C D 11 c^{+}$cells as described in fig 4. (A) Proliferative responses (left), IFN- $\gamma$ secretion (midde), and IL4 secretion (right) by hepatic $\mathrm{CD} 4^{+} \mathrm{T}$ cells were measured

16 hours after the induction of hepatitis.

Hepatic or splenic $\mathrm{CD} 4^{+} \mathrm{T}$ cells $\left(1 \times 10^{5} /\right.$ well $)$ were stimulated with OVA-peptide $(1 \mu \mathrm{g} / \mathrm{ml})$ presented by irradiated splenocytes $\left(5 \times 10^{5}\right)$ well) from $B A L B / c$ mice. (B, C) Flow

cytometric analysis of $\mathrm{IHLs}$ or splenocytes in the mice transferred with hepatic $C D 11 \mathrm{c}^{+}$

cells from mice fed PBS or OVA followed by the induction of OVA-specific hepatitis. IHLs or splenocytes were stained with KJ1-26 FITC $\mathrm{mAb}$, anti-CD4 PE mAb, and biotinylated Annexin V followed by streptavidin-RED670. An analysis gate was set on $\mathrm{CD} 4^{+} \mathrm{KJ} 1-26^{+}$ cells for Annexin $\mathrm{V}$ binding assay. The number in each panel shows the percentage of $\mathrm{CD} 4^{+} \mathrm{KJ} 1-26^{+} \mathrm{T}$ cells $(\mathrm{B})$ or Annexin $\mathrm{V}^{+}$ cells in CD4 $4^{+} \mathrm{KJ} 1-26^{+} \mathrm{T}$ cells (C). ${ }^{*} \mathrm{p}<0.05$, ${ }^{* *} p<0.01$ versus PBS control. The results are expressed as meanSD. The results shown are representative one of two independent experiments ( $n=3$ in each group).
Thus, induction of Th2 responses, rather than Th1, and apoptosis of activated $\mathrm{T}$ cells seem to be shared properties of some hepatic DCs. This notion fits well to our previous finding in that $\mathrm{CDIIC}^{+}$class $\mathrm{II}^{+}$cells in the periportal and sinusoidal areas take a soluble Ag (OVA) administered orally and present the $\mathrm{Ag}$ to Ag-specific $\mathrm{CD}^{+} \mathrm{T}$ cells, which finally generates regulatory Th2 cells expressing Fas ligand. ${ }^{8}{ }^{16}$ Thus, some liver DCs, capturing dietary Ags and being activated by materials contained in portal blood flow, generates tolerogenic Th2 cells. The similar property was shared by LSECs which can induce Th2 responses in vitro. ${ }^{9}$ However, LSECs have an additional function and induce tolerogenic responses by $\mathrm{CD}^{+} \mathrm{T}^{+}$cells. ${ }^{21} 22$ In contrast to these tolerogenic APCs, Kupffer cells present Ags and lead to development of Thl type inflammatory response in the liver. In fact, Kupffer cells are known to capture OVAliposome and elicit hepatitis by presenting OVA to $\mathrm{CD}^{+} \mathrm{T}$ cells in our model. ${ }^{14}$

As to a mechanism how some liver DCs are involved in the generation of Th2 cells, our knowledge has been very limited. We previously showed that DCs deficient in IL12 secretion play an important role. ${ }^{8}$ It was also seen in this study that neutralisation of IL12 signalling enhanced apoptosis and IL4 production by the naïve $\mathrm{CD} 4^{+} \mathrm{T}$ cells that were presented an $\mathrm{Ag}$ by hepatic $\mathrm{CDIlc}^{+}$cells of PBS-fed mice. By contrast, restoration of IL12 signalling abolished apoptosis and IL4 production when an $\mathrm{Ag}$ was presented by hepatic CDI lc ${ }^{+}$cells of OVA-fed mice (fig 3). Furthermore, we showed that Fas-Fas ligand interaction between Ag-activated $\mathrm{CD}^{+}{ }^{+} \mathrm{T}$ cells deletes Thl cells and results in survival of Th2 cells which are less 
dependent on IL12 and more resistant to Fas-mediated apoptosis than Thl cells. ${ }^{8}$ Therefore, CDl $\mathrm{Cc}^{+}$cells deficient in IL12 secretion enhance not only Th2 differentiation but also apoptosis of Thl cells. This property of DCs explains the results that transfer of hepatic DCs of OVA-fed mice rendered recipients resistant to hepatitis and gave rise to Th2 responses and apoptosis of $\mathrm{CD} 4^{+} \mathrm{T}$ cells in the liver. Thus, in the absence of these periportal and sinusoidal DCs, OVA presentation by Kupffer cells alone would have resulted in clonal expansion of OVA-specific Thl cells and caused hepatitis. ${ }^{14}$

Having stated above conclusion, we consider the pathogenic roles DCs might play in some disease conditions. For instance, some functions of DCs are impaired in the patients with AIH or PBC. ${ }^{23}$ DCs from patients with PBC present pyruvate dehydrogenase complex and cause proliferation of patients' $\mathrm{T}$ cells. ${ }^{24}$ Considering that Thl cytokines are associated with development of hepatitis, one would ask the role of IL12 produced by liver DCs in the pathogenesis of above diseases. In fact, Kanto et al reported increase of IL12 secretion by DCs of the patient with HCV-hepatitis when pulsed with HCV core-Ag. ${ }^{25}$ However, we should take note that all studies cited above utilised DCs and T cells in peripheral blood, so that immune responses seen in vitro do not necessarily reflect those occurring in the liver. Holding above reservation and assuming that pathogenic DCs invariably produce IL12, the function of DCs described here and in our previous studies ${ }^{8}$ could suggest a distinct subset of liver DCs. As shown in this study, the DCs transfer the resistance to hepatitis caused by Thl cells. Thus, the periportal and sinusoidal DCs, which take Ags in the portal vein, might physiologically tilt the immune response to Th2 to balance excessive Thl responses elicited by systemic Ags in the liver.

Finally we consider another aspect of the role these liver DCs might play. We showed that adoptive transfer of hepatic DCs of OVA-fed mice leads to an increase of IgE Abs in the sera of recipient mice after systemic OVA challenge. This could imply a role liver DCs might play in food allergy. As most of the food allergy cases associate with an increase of IgE responses to Ags digested, ${ }^{26}$ food Ag-specific Th2 cells are essential for the pathogenesis. However, the generation of those Th2 cells has not been known well. Our result here suggests that the liver is the site wherein those Th2 cells can develop. In fact, some animal studies suggest that the liver is the organ where the induction of systemic IgE response occurs, ${ }^{27} 28$ In human studies, a case report described that peanut allergy was transferred to the recipient of the liver transplant, not to the recipient of the kidney and pancreas of the same donor..$^{29}$ Compatible to these, we previously reported that helper $\mathrm{T}$ cells for IgE response to a dietary Ag develop in the liver, but not in Peyer's patches or the spleen. ${ }^{18} \mathrm{We}$ show here that periportal and sinusoidal DCs loaded with OVA in vivo are sufficient to transfer systemic Th2 response to OVA in recipient mice. Taken together, we argue that dietary Ags can develop liver DCs which direct naïve $\mathrm{Ag}$-specific $\mathrm{CD} 4^{+} \mathrm{T}$ cells to Th2. We speculate that if frequency of the Ag-specific CD4 ${ }^{+} \mathrm{T}$ cells is high and the amount of IL4 accumulated is large enough, then IgE produced as a result would reach to a pathogenic level. In a physiological context, the presence of DCs, which can generate Th2 response to portal Ags and prevent liver injury caused by Thl cells specific to systemic Ags, might indicate a counter-regulatory mechanism in the liver. In a theoretical extension, this might suggest that Thl-mediated liver disease can be treated by targeting pathogenic Ags to portal blood flow, with careful control of allergic reactions.

\section{Authors' affiliations}

Tomohiro Watanabe, Hiroaki Katsukura, Yoshio Wakatsuki, Department of Clinical Bio-regulatory Science, Kyoto University Graduate School of Medicine, Kyoto, Japan
Tomohiro Watanabe, Tsutomu Chiba, Department of Gastroenterology and Hepatology, Kyoto University Graduate School of Medicine, Kyoto, Japan

Toru Kita, Department of Cardiovascular Medicine, Kyoto University Graduate School of Medicine, Kyoto, Japan

Funding: This work was supported in part by grants from the Ministry of Education, Science and Culture, Japan, the Japan Society for the Promotion of Science (JSPS) and the Ministry of Health, Labor and Welfare.

Competing interests: None.

\section{REFERENCES}

1 Crispe IN, Giannandrea M, Klein I, et al. Cellular and molecular mechanisms of liver tolerance. Immunol Rev 2006;213:101-18.

2 Crispe IN. Hepatic T cells and liver tolerance. Nat Rev Immunol 2003;3:51-62.

3 Thomson AW, Lu L. Are dendritic cells the key to liver transplant tolerance? Immunol Today 1999;20:27-32.

4 Thomson AW, Drakes ML, Zahorchak AF, et al. Hepatic dendritic cells: immunobiology and role in liver transplantation. J Leukoc Biol 1999;66:322-30.

5 Callery MP, Kamei T, Flye MW. The effect of portacaval shunt on delayedhypersensitivity responses following antigen feeding. J Surg Res 1989;46:391-4.

6 Shapiro AM, Lakey JR, Ryan EA, et al. Islet transplantation in seven patients with type 1 diabetes mellitus using a glucocorticoid-free immunosuppressive regimen. N Engl J Med 2000;343:230-8.

7 Lau AH, Thomson AW. Dendritic cells and immune regulation in the liver. Gut 2003;52:307-14.

8 Watanabe T, Katsukura $\mathrm{H}$, Shirai $\mathrm{Y}$, et al. A liver tolerates a portal antigen by generating $C D 11 \mathrm{c}$ cells, which select Fas Ligand Th2 cells via apoptosis. Hepatology 2003;38:403-12.

9 Knolle PA, Schmitt E, Jin S, et al. Induction of cytokine production in naive CD4(+) $\mathrm{T}$ cells by antigen- presenting murine liver sinusoidal endothelial cells but failure to induce differentiation toward Th1 cells. Gastroenterology 1999; 1 16:1428-40.

10 Khanna A, Morelli AE, Zhong C, et al. Effects of liver-derived dendritic cell progenitors on Th1-and Th2- like cytokine responses in vitro and in vivo. J Immunol 2000;164:1346-54.

11 Czaja AJ, Cookson S, Constantini PK, et al. Cytokine polymorphisms associated with clinical features and treatment outcome in type 1 autoimmune hepatitis. Gastroenterology 1999; 117:645-52.

12 Harada K, Van de Water J, Leung PS, et al. In situ nucleic acid hybridization of cytokines in primary biliary cirrhosis: predominance of the Th1 subset. Hepatology 1997;25:791-6.

13 Bo X, Broome U, Remberger $M$, et al. Tumour necrosis factor alpha impairs function of liver derived T lymphocytes and natural killer cells in patients with primary sclerosing cholangitis. Gut $2001 ; 49: 131-41$.

14 Nishimura T, Ohta A. A critical role for antigen-specific Th1 cells in acute liver injury in mice. J Immunol 1999;162:6503-9.

15 Tjandra K, Sharkey KA, Swain MG. Progressive development of a Th1-type hepatic cytokine profile in rats with experimental cholangitis. Hepatology 2000;31:280-90

16 Watanabe T, Yoshida M, Shirai Y, et al. Administration of an antigen at a high dose generates regulatory CD4+ T cells expressing CD95 ligand and secreting IL4 in the liver. J Immunol 2002;168:2188-99.

17 Watanabe T, Yamori M, Kita T, et al. CD4+CD25+ T cells regulate colonic localization of CD4 T cells reactive to a microbial antigen. Inflamm Bowel Dis $2005 ; 11: 541-50$

18 Watanabe T, Katsukura H, Shirai Y, et al. Helper CD4 T cells for lgE response to a dietary antigen develop in the liver. J Allergy Clin Immunol 2003;1 11:1375-85.

19 Watanabe T, Kitani A, Murray PJ, et al. Nucleotide binding oligomerization domain 2 deficiency leads to dysregulated TLR2 signaling and induction of antigen-specific colitis. Immunity 2006;25:473-85.

20 Lu L, Bonham CA, Liang X, et al. Liver-derived DEC205+B220+CD19-dendritic cells regulate T cell responses. J Immunol 2001;166:7042-52.

21 Limmer A, Ohl J, Wingender G, et al. Cross-presentation of oral antigens by liver sinusoidal endothelial cells leads to CD8 T cell tolerance. Eur J Immunol 2005;35:2970-81.

22 Knolle PA. Involvement of the liver in the induction of CD8 T cell tolerance towards oral antigen. Z Gastroenterol 2006;44:51-6.

23 Hiasa Y, Akbar SM, Abe M, et al. Dendritic cell subtypes in autoimmune liver diseases; decreased expression of HLA DR and CD123 on type 2 dendritic cells. Hepatol Res 2002;22:241-249.

24 Akbar SM, Yamamoto K, Miyakawa H, et al. Peripheral blood T-cell responses to pyruvate dehydrogenase complex in primary biliary cirrhosis: role of antigenpresenting dendritic cells. Eur J Clin Invest 2001;31:639-46.

25 Kanto T, Hayashi N, Takehara T, et al. Impaired allostimulatory capacity of peripheral blood dendritic cells recovered from hepatitis $C$ virus-infected individuals. J Immunol 1999;162:5584-91

26 Sicherer S. Food allergy. Lancet 2002;360:701

27 Collins AM, Leach S, Payne J, et al. A role for the hepatobiliary system in lgEmediated intestinal inflammation in the rat. Clin Exp Allergy 1999;29:262-70.

28 Ito K, Inagaki-Ohara K, Murosaki S, et al. Murine model of IgE production with a predominant Th2-response by feeding protein antigen without adjuvants. Eur J Immunol 1997;27:3427-37.

29 Legendre C, Caillat-Zucman S, Samuel D, et al. Transfer of symptomatic peanut allergy to the recipient of a combined liver-and-kidney transplant. N Engl J Med 1997;337:822-4. 